\title{
Development of a trip profile for elderly American casino visitors
}

Received (in revised form): 19 September 2006

\begin{abstract}
A. J. Singh
is an associate professor in The School of Hospitality Business at Michigan State University. His research focuses on lodging operations and finance and has published in the Cornell Hotel and Restaurant Administration Quarterly, International Journal of Hospitality Management, FIU Hospitality Review and other academic publications.
\end{abstract}

\section{Omar Moufakkir}

has a PhD in Parks Recreation and Tourism from Michigan State University (2002). The focus of his research is to understand gaming behaviour and casino visitation patterns. He has led various research studies related to gaming and recreation in Michigan. He currently teaches at $\mathrm{CHN}$ University in Leewarden, in The Netherlands.

\section{Donald F. Holecek}

is the Director of Travel Tourism and Recreation Resource Center at Michigan State University. The focus of his research is tourism marketing. The centre conducts and sponsors research studies related to travel and tourism in Michigan.

\section{Abstract}

The US population is aging and those aged 65 years and older constitute an important segment of the population. One-half of those aged 65 years and older participated in casino gaming in 1998 (approximately 16 million), and this number is expected to increase with the increasing number of casinos and the growing number of the elderly. In reality, casino gaming already attracts a large number of elderly people. However, research on the elderly, who participate in this activity for recreation, is less visible in the academic literature. Furthermore, much of the literature on gaming has been traditionally focussed on addiction or the economic and social impacts of casino gaming development on local economies. As recreation providers, there is also a need to focus on ways to make this recreational activity worthwhile and thereby contribute to the well being of this growing population who likes to gamble. The focus of this study was to examine the casino trip characteristics of elderly Americans to two of the largest casinos in Michigan. The results of this study will be useful

\section{A.J. Singh}

The School of Hospitality Business Eli Broad College of Business Michigan State University East Lansing, Michigan 48824

Tel: +15173539211

Fax: +15174321170

E-mail: singharj@msu.edu for casino operators and marketers who want to understand the characteristics of this lucrative segment of the gaming population.

\section{Keywords:}

elderly, casino gaming, leisure, recreation, market segmentation

Journal of Retail and Leisure Property (2007) 6, 61-68.

doi:10.1057/palgrave.rlp.5100044 


\section{INTRODUCTION}

People have now become familiar with the demographic fact that the US population is aging. Figures from the US Census Bureau indicate that those 65 years and older numbered 35.0 million in 2000, an increase of 3.7 million or 12.0 per cent since 1990 . About one in every eight, or 12.4 per cent of the population is 65 years or older. In 2000, persons reaching age 65 years had an average life expectancy of an additional 17.9 years (19.2 years for females and 16.3 years for males). By year 2030, the population of elderly Americans will more than double to about 70 million. ${ }^{1}$

Recognising the importance of this growing demographic segment, in 1982, the United Nations adopted the slogan: 'To add life to the years that have been added to life.' It also declared the year 1999 to be the 'International year of older persons'. Recognising the importance of leisure in achieving and maintaining well being in later life, the World Leisure and Recreation Association (WLRA) recently established a new commission on later life. According to the WLRA, in the decades ahead, those 65 and older will continue to pursue an active lifestyle. ${ }^{2}$

Research of this segment of the population will provide hospitality and social science researchers, policymakers and managers, relevant information that will allow their businesses and services to effectively meet the needs of an aging population. Organisations may view the transformation of the elderly population as a threat or an opportunity. If they are unprepared to meet the shifting needs of this customer base, they may view these changes as a threat, while those willing to adapt will see this as an opportunity to capture a larger market share and increase revenues.

In general, studies focussing on the elderly are rare, ${ }^{3}$ and those focusing on the elderly and gaming are almost non-existent. Of the studies that focused primarily on gaming and the elderly, Tarras et al. ${ }^{4}$ examined the gaming behaviour of elderly women, Higgins ${ }^{5}$ focussed on the senior centre gambling trips and Petry ${ }^{6}$ addressed the elderly and gambling addiction. This study focusses specifically on the casino trip characteristics of elderly Americans. By profiling the typical trip characteristics of this gaming cohort, policymakers, casino managers, tourism marketers and senior centres will be better able to serve this important constituency.

\section{DEFINING AN ELDERLY PERSON}

A review of the literature revealed that there was no consensus among researchers about age group categorisations or age terminology of elderly people. Some of the categories and terms used by researchers include, 'Older Americans', 6 'Older Seniors and Younger Seniors', 'Seniors', 8,10 'Senior Adults', ${ }^{10}$ 'Young Old, Old-Old, Oldest-Old', 'Senior Market', 12 'Elderly' ${ }^{4}$ and 'The World War II Generation'. ${ }^{13}$ This clear lack of agreement on a uniform label for this cohort makes comparison across existing studies about the elderly difficult.

For the purposes of the present study, the categorisation used by The US Administration on Aging (AoA) ${ }^{14}$ was used to define an elderly 
person. The AoA uses $65-74,75-84$ and 85 years and over as age groups to categorise the elderly population. Following the tradition set by the AoA, this study defines the elderly as those aged 65 years and older.

\section{PURPOSE OF THE STUDY}

Given the size of this gaming cohort, their propensity to visit casinos (National Opinion Research Center reported that 50 per cent of elderly Americans participated in casino gaming in 1998) and their growth potential as a market segment, the primary motivations for undertaking this study were to improve our understanding of this group. We plan to assemble a comprehensive profile of elderly Americans, based on an analysis of their typical casino activities. The variables identified for the study were designed from the perspective of a marketing manager, who is interested in understanding the travel behaviour and gambling motivations of this market segment. Specifically, the study seeks to answer the following five questions about a typical casino trip by an elderly American:

1. What is the typical profile of a casino trip?

2. What is the typical spending profile on a casino trip?

3. How do they budget for the casino trip?

4. What are the sources of information for planning a casino trip?

5. What are their package preferences and weekly distribution of their visits?

\section{METHODOLOGY}

The data analysed for this paper are a subset of the data collected by the authors for a larger research project titled, 'Detroit Metro Area Casino Visitor Study'. ${ }^{15}$ The primary impetus for the broader study was to measure the economic impact of out-of-town casino visitors. This study was conducted in two phases: The Intercept and screening phase, conducted onsite at two major casinos in Michigan, and the follow-up interview phase, conducted via telephone from the Travel Tourism and Recreation Resource Centre at the Michigan State University.

The first phase involved intercepting casino visitors in the non-gaming areas of the casinos and asking them a set of preliminary questions. Two weekdays and two weekends were randomly selected each month as sampling periods, with intercepts taking place between 10:00am and 4:00pm, and between 4:00pm and 10:00pm A total of 9,099 casino visitors were intercepted over a five-month period from May to September 2003.

In the first screening question, locals (residing in Metro Detroit Area) were separated from nonlocals (outside Metro Detroit area). Of the total 9,099 intercepts, 1,887 (20.7 per cent) were classified as nonlocals. This group represented the sample frame for the study and follow-up interview phase. 
A. J. Singh et al.

Table I: Typical travel profile of elderly American casino visitors

\begin{tabular}{|c|c|c|c|c|c|c|c|c|c|}
\hline Response & $\begin{array}{l}\text { First trip to } \\
\text { casino (\%) }\end{array}$ & $\begin{array}{l}\text { Over-night } \\
\text { stay (\%) }\end{array}$ & $\begin{array}{l}\text { Hotel motel } \\
\text { stay (\%) }\end{array}$ & $\begin{array}{l}\text { Stay with } \\
\text { friends and } \\
\text { relatives (\%) }\end{array}$ & $\begin{array}{l}\text { Casino as } \\
\text { primary trip } \\
\text { motivation (\%) }\end{array}$ & $\begin{array}{l}\text { Visits to } \\
\text { other } \\
\text { casinos (\%) }\end{array}$ & $\begin{array}{l}\text { Other } \\
\text { recreation } \\
\text { on trip (\%) }\end{array}$ & $\begin{array}{l}\text { Travel } \\
\text { single (\%) }\end{array}$ & $\begin{array}{l}\text { Travel with } \\
\text { children (\%) }\end{array}$ \\
\hline Yes & 57.6 & 27.5 & 69.0 & 28.6 & 65.9 & 32.4 & 39.4 & 14.1 & 7.6 \\
\hline No & 42.4 & 72.5 & 31.0 & 71.4 & 34.1 & 67.6 & 60.6 & 85.9 & 92.4 \\
\hline
\end{tabular}

The second phase involved administering the follow-up telephone interview. The questionnaire used in the interview was designed to gather specific information about each visitor's most recent trip to a Detroit casino, which included travel behaviour and those specifically related to casino visits. The telephone survey instrument was developed over a period of two months, and pilot tested on 50 Detroit casino patrons, before implementing the final version. The final report was based on 853 completed and usable questionnaires.

For the purposes of this paper, a convenience sample of 170 respondents, aged 65 years and over, was selected from this data set of 853 cases. The vast majority of the respondents ( 85 per cent) in the sample were retired, virtually none (95.3 per cent) had children in their household and the majority were married or divorced (59 per cent and 30 per cent, respectively). Nearly one-half had a household income under $\$ 37,000$, while almost 12 per cent said their household income in 1999 was over $\$ 50,000$. The demographic characteristics of the elderly American gamers selected for the study are similar to those of the overall US elderly population.

\section{ANALYSIS OF RESULTS Trip characteristics}

As noted in Table 1, most elderly casino visitors (57. 6 per cent) were visiting a casino for the first time. Hotel accommodations were not a primary concern on these visits as only about 27 per cent of the respondents indicated that they planned to stay overnight. Of those who responded that they would spend the night, 69 per cent indicated that they would use a hotel or motel facilities while about 29 per cent said that they would stay with friends and relatives. As such, while this age group is predominantly a day-tripping market, those who do stay overnight most likely would use commercial facilities. Elderly Americans going on these trips travel for the express purpose of visiting a casino (65.9 per cent), and one-third of this group visits other casinos while they are travelling. Given the particulars of their demographic profile, this segment mainly travels alone and almost none travel with children (Table 1).

\section{Trip spending}

Based on the reported data, the elderly American casino visitor is mainly a budget conscious traveller, spending on average $\$ 32.00$ per night on hotel accommodations. Interestingly, they spend as much on food and beverage outside the casino as on lodging (\$33.00). The fact that they 
Table 2: Comparative analysis of financial planning of casino visitors

\begin{tabular}{ll}
\hline Do you set a budget for your trip? & $\%$ \\
\hline Never & 13.3 \\
Sometimes & 26.7 \\
Always & 60.0 \\
\hline
\end{tabular}

Table 3: Primary source of trip information for elderly American casino visitors.

\begin{tabular}{lllllll}
\hline $\begin{array}{l}\text { Information } \\
\text { need }\end{array}$ & $\begin{array}{l}\text { Friends and } \\
\text { relatives (\%) }\end{array}$ & $\begin{array}{l}\text { Internet } \\
(\%)\end{array}$ & $\begin{array}{l}\text { Direct mail } \\
(\%)\end{array}$ & $\begin{array}{l}\text { Newspaper } \\
\text { (\%) }\end{array}$ & $\begin{array}{l}\text { Magazine } \\
\text { (\%) }\end{array}$ & $\begin{array}{l}\text { Radio } \\
\text { television (\%) }\end{array}$ \\
\hline $\begin{array}{l}\text { Information } \\
\text { for casino } \\
\text { Information } \\
\text { for community }\end{array}$ & 70.8 & 4.9 & 7.3 & 4.9 & 0.0 & 9.8 \\
\hline
\end{tabular}

Totals will not equal $100 \%$ as table only reflects percentage of respondents who identified an information channel

spend more outside the casino versus inside a casino may imply either that casinos are not offering the type of food that they prefer or that the price-value relationships are more favourable in food and beverage facilities outside the casino. Average gasoline expenditures of $\$ 6.00$ and $\$ 8.00$ for miscellaneous items indicate that this is not a major expense item for their trip. The low gas expenditures may be indicative of shorter distance trips or free bus trips organised by casinos to bring these players to their destination.

\section{Financial planning of casino trips}

Based on findings, Elderly American gamers are good planners (Table 2). Most participants (60 per cent) in the survey indicated that they always budget for these trips, while about 27 per cent said that they do so sometimes. A majority of the participants will prepare a budget for each gaming trip. These results indicate a budget conscious traveller who will value efforts by casinos to assist in his or her trip planning. As such, this gamer would prefer to know ahead of time how much they will spend on food, lodging, gaming and other expenses on these trips. Casinos that can organise packages with these predetermined numbers will most likely be more popular with this elderly population. Based on findings reported in the broader Casino visitor study, while younger casino visitors budget for casino trips, the percentage was not as high as the elderly population.

As with other trip expenditures, elderly gamers do not have high gaming losses. The elderly casino visitor's average reported loss was $\$ 118.31$, with a maximum reported loss of $\$ 3,000$. Once again, this points to a conservative market segment that comes to a casino with a predetermined loss expectation and may not exceed that amount. As a result, for casinos, this is a high volume market segment, as their average earnings from each elderly customer are expected to remain low. While not the focus of this paper, a comparison of the gaming losses of elderly 
Table 4: Weekly distribution of visitation

\begin{tabular}{ll}
\hline When do you prefer to visit the casino? & $\%$ \\
\hline Prefer weekday & 55.6 \\
Prefer weekend & 25.4 \\
No preference & 18.9 \\
\hline
\end{tabular}

Table 5: Package preferences of elderly casino visitors

\begin{tabular}{ll}
\hline Package preferences & $\%$ \\
\hline Use of package & 53 \\
Day package & 32.2 \\
Overnight package & 34.0 \\
No preference (package type) & 33.3 \\
Weekday package & 47.2 \\
Weekend package & 23.6 \\
No preference (day of week) & 29.2 \\
\hline
\end{tabular}

gamers to other segments (reported in the broader Casino visitor study) shows them to have the lowest average loss. The highest being the age segment 18-34 years, with average losses of \$206.52.

\section{Trip information}

Based on findings, when planning or deciding on a casino trip, the traveller gets information about the community and specifically the casino. About one-fourth of the elderly obtained information about the casino before their trip. They were more likely than the other age groups to do so. As noted in Table 3, about 10 per cent of the travellers got their information from the radio or television. Similarly, the internet and direct mail also feature low in their trip planning information sources (4.9 and 7.3 per cent, respectively). When advertising and promoting to this group, it is important for casino companies to focus on the importance of wordof-mouth advertising. As most hear about a facility through friends and relatives (70.8 per cent), a satisfied guest, in this case, is the casino's best spokesperson for repeat visits and new business development.

Most elderly casino visitors to a casino do not learn about the community before they visit; only 10 per cent indicated that they do so. We need to cautiously interpret these results, as most of the respondents for this survey were most likely Michigan residents who are familiar with the city to which they are travelling. As in the case of casino information, elderly travellers primarily rely on friends and relatives for information about the community (58.8 per cent). Interestingly, even though the internet was not a major source of information for casino trip information and planning, this was a substantially more popular method of learning about the community (11.8 per cent). It appears that the elderly do use the internet in a limited way, but for some reason, they do not use the internet to learn about specific casinos. Perhaps, casino companies need to promote the use of their sites through effective links to destination marketing websites. Other equally important information channels were 
magazines, which are used by 11.8 per cent of the respondents. Direct mail, once again, is not an effective method of learning about casinos.

\section{Gaming visitation and package preferences}

As noted in Table 4, weekdays were the most popular time to visit casinos, with more than 50 per cent selecting that time. As reported in the broader casino visitor study, casinos are more crowded on the weekends with a younger market, which may be the reason why only 25 per cent of the elderly respondents preferred going to casinos on the weekend. Even though the likelihood of winning and losing is the same on any given day of the week, this age cohort prefers a relatively quieter experience that is less busy with people, with more open machines and tables, and takes comfort in the homogeneity of the atmosphere.

Packages are the best way to attract elderly gamers to casinos with more than one-half of the elderly saying that they were interested in a package tour that includes gaming (Table 5). They were evenly distributed in their choice of a day or overnight package and the same number had no decided preference on a package. However, not surprisingly, most elderly gamers wanted their packages to be designed for weekday trips versus weekend trips.

\section{Summary and implications for casino management}

With regard to their trip characteristics, they are more likely than individuals who are younger than 65 to be first-time visitors. They are the least likely to stay overnight, but are more likely to visit other casinos while on a trip. This segment is budget conscious and meticulously plans their trip. As the majority gets their casino information from friends and family, word-of-mouth advertising is a critically important source of information to attract this demographic group. Offering them a gaming package that includes an experience at different casinos would improve their overall trip experience and make them stay overnight, especially since the greatest majority of them reported that they are interested in package tours that include stops at casinos.

This paper was limited to elderly people who visited two (albeit the largest casinos in Michigan) commercial casinos in the Detroit area. We do not know, however, if their trip characteristics and gaming behaviour are different from those who patronise Indian casinos or those in Atlantic City or Las Vegas. Furthermore, the tendency of tourism marketers and product developers has been to treat this age group as one homogeneous segment. ${ }^{9}$ However, researchers have indicated that elderly people as a market segment are diverse with respect to socioeconomic, demographic characteristics, lifestyles, interest, attitude and consumption patterns. ${ }^{9}$ In general, to cater to the diverse needs of this growing market, we need a more comprehensive understanding of their travel behaviour. ${ }^{9}$ This will further help us to broaden our understanding of their recreational needs, interests and behaviours. Because the elderly like to enjoy casinos and gaming has become a part of their leisure repertoire, ongoing research and investigation into their gaming trip behaviour will provide guidance 


\section{to casino operators to exceed guest expectations and provide highly enjoyable experiences.}

\section{References and Notes}

1. Administration on Aging (2005). Older population by age: 1900 to 2050. Administration on Aging, http://www.aoa.gov/prof/Statistics/online_stat_data/AgePop2050.asp, Accessed 31st October 2006.

2. Commission on Leisure and Life, Purpose and Goals (2005). www.worldleisure.org.

3. Strain, L., Grabusic, C.C., Searle, M.S. \& Dunn, N.J. (2002). Continuing and ceasing leisure activities in later life: A longitudinal study. The Gerontologist. 24(2), 217-224.

4. Tarras, J., Singh, A. \& Moufakkir, O. (1999). The profile of gambling behavior of elderly women gamblers. Gambling Research and Review Journal. 5(1), 33-45.

5. Higgins, J. (2001). A comprehensive policy analysis of recommendations for senior center gambling trips. Journal of Aging and Social Policy. 12(3), 73-91.

6. Petry, M.N. (2002). A comparison of young, middle-aged and older adult treatment seeking pathological gamblers. The Gerontologist. 42(1), 92-99.

7. Backman, K.F., Backman, S.J. \& Silverberg, K.E. (1999). An investigation into the psychographics of senior nature-based travelers. Tourism Recreation Research. 24(1), 13-22.

8. Javalgi, R.G., Thomas, E.G. \& Rao, S.R. (1992). Consumer behaviour in the U.S. pleasure travel market place: An analysis of senior and non-senior travelers. Journal of Travel Research. 31(2), 14-19.

9. Horneman, L.R., Carter, W., Wei, S. \& Ruys, H. (2002). Profiling the senior traveler: An Australian perspective. Journal of Travel Research. 41, 23-37.

10. Cordes, K.A. \& Ibrahim, H.M. (1999). Application in recreation \& leisure for today and the future 2nd edn WCB McGraw-Hill, Boston Burr Ridge, IL.

11. Chou, K.L \& Chi, I. (2002). Successful aging among the young-old, old-old, and oldest-old Chinese. The International Journal of Aging \& Human Development. 54(1), 1-15.

12. Shoemaker, S. (1989). Segmentation of the senior travel market. Journal of Travel Research. 27(3), 31-38.

13. Mitchell, S. (2000). American generations: Who they are. How they live. What they think, 3rd edn, New Strategist Publications Inc, Ithaca, NY.

14. AoA is the federal focal point and advocate agency for older persons and their concerns. As such, in their role as the advocacy group for older Americans, AoA works to heighten awareness among federal agencies, organisations, groups and the public about valuable contributions made by older Americans.

15. References to this study are made in the text when comparison with a younger age cohort is relevant to the discussion and interpretation of results. 